\title{
Fermilab Library Projects *
}

\author{
P. Garrett and D. Ritchie \\ Fermi National Accelerator Laboratory \\ P.O. Box 500 \\ Batavia, Illinois 60510
}

May 3, 1990

* Submitted to the First Inter-Laboratory Workshop on Preprint Database Management, Geneva, Switzerland, May 14-16, 1990. 


\section{FERMILAB LIBRARY PROJECTS}

\subsection{Introduction}

Preprint database management as done at various centers--the subject of this workshop-is hard to separate from the overall activities of the particular center. We therefore present the wider context at the Fermilab Library into which preprint database management fits.

The day-to-day activities of the Library aside, the dominant activity at present is that of the ongoing Fermilab Library Automation Project. A less dominant but relatively time-consuming activity is that of doing more online searches in commercial databases on behalf of laboratory staff and visitors. A related activity is that of exploring the benefits of end-user searching of similar sources as opposed to library staff searching of the same.

The Library Automation Project, which began about two years ago. is about to go fully "online". The rationale behind this project is described in the documents developed during the December 1988-February 1989 planning phase.

Much of that rationale still holds and is described in the following pages. As it was addressed to an audience unfamiliar with many detailed aspects of managing a library. it is somewhat tutorial. For this workshop. this is clearly unnecessary. We ask that the reader overlook this particular style and. instead. take from the text a sense of the directions specified in the one year old plan which we are still in the processing of executing.

A companion document. Fermilab Library Directions, also submitted to this Workshop. amplifies on the overall directions which were just beginning to be sensed at the time the Automation Project plans were put in place. In that companion document, we attempt to update our directions in the light of the technological changes that have occurred in the interval: the accelerated emphasis on networking (particularly. TCP/IP and Internet). the rise to prominence of UNIX on the laboratory scene, the development of $X$ windows terminals, etc.

\subsection{Why Automote?}

Fermilab conducts its research principally through group collaborations. The researchers in these collaborations are based at home institutions throughout the United States. In addition, visitors from institutions in foreign countries are often involved.

This research extends over many months (sometimes years) during which time the researchers are alternately at Fermilab and then at their home institutions (e.g.. fulfilling their teaching commitments, etc.). The research often involves frequent references to technical books. periodicals, current journal publications, or even material so recent as to not even be published (these are referred to as "preprints").

Access to much of this material is obtained through the Fermilab Library. A critical requirement is that access to this material be provided in a timely fashion. There are two levels of access: first, provision of "card" catalog information and, second, provision of the actual information itself. If either or both levels of access could be provided more quickly and in an automated manner, advantages to the research process would accrue. 
Finally, there is the matter of easing the management of the holdings.

Access to Catalog: The provision of automated, electronic access to the catalog for those visiting the Library would be advantageous because of the increased ability to survey more possible sources--including those that might be otherwise overlooked because of complex cross referencing. The provision of a similar capability for those at other areas within the Laboratory would be even more advantageous--they would know whether or not the Library held the material and. ideally, whether or not it was checked out before making the trip to the Library. Finally. the provision of this capability for those at their home institution would allow them to develop possible sources of information. These could then be obtained from their home institution's libraries or from the Fermilab Library on their next visit to the Laboratory.

Access to Information: The provision of access to the information itself in a more automated and electronic manner would aid the research process even further. Fewer trips to the Library for the actual material would be necessary. The inclusion of information into one paper from a previous one would be made more straight-forward: the need to re-type information from one document into another would be lessened. Since much of the technical memoranda and papers produced at Fermilab are already prepared in electronic form. the provision of this level of access for a very important category of documents--those documents developed locally--is considerably easier than for the remaining category of documents-those developed and/or published elsewhere.

Easing the Management of the Holdings: The provision of an automated. electronic mechanism for the library staff to use in managing the holdings would be advantageous as well. The business of obtaining. cataloging. and placing new material into the library holdings--as well as the business of tracking the location and status of existing material--presently involves time-consuming. manual procedures. Automation would result in efficiencies and allow effort to be focused on improving the collection.

As an example of what must currently be handled on a manual basis. note that between 450 and 550 high-energy physics preprints are received in the library each month. These must be cataloged and made available to interested individuals. This requires updates to the card catalog. placement of the preprints on the shelves. circulation of the preprints to interested parties. the culling out of those preprints that have been published. etc. An automated system would simplify the cataloging and the circulation aspects.

\subsubsection{What is the Current Library/HEP-Programmatic Environment?}

The Book Collection (including the proceedings of conferences): The Book Collection covers detector Jevelopment, accelerator technology, theoretical physics, etc. The Library processes approximately 100-150 books per month. Beginning in 1982, the Library's holdings have been entered online into the OCLC (the Online Computer Library Center) database. OCLC is a company which provides a bibliographic cataloging service. Pre1982 holdings have not been converted. Note that OCLC is designed for access by professional librarians--not the library patron--as an aid to doing the cataloging prior to placing an item in the Library collection. It is not amenable to general use: its relevance here is that most library automation packages make provision for the downloading of a library's holdings from the OCLC database.

Programmatically, this collection provides the basic reference works fundamental to the pursuit of the Laboratory's research efforts. Researchers often need to apprise 
themselves of the work done elsewhere and/or use the results of this work in developments done at Fermilab. Typically. though not always. this Collection provides information on established technologies. The collection handles the needs of a wide range of users. from the machinist to the vacuum technologist--not just those of the high energy physicist.

The Journal Collection: The Journal Collection provides the definitive record in regard to high-energy physics experiments results, analyses of those results, and theories of the phenomena observed. Current library subscriptions number 175: most of these have been cataloged with the aid of OCLC.

Programmatically. journals provide recent research results in many specialized areas. As recent results, they are unlikely to have been published in book form. The information in these journals is important when comparing the results of ongoing high energy physics work against the results of previous experiments done at other laboratories. To a greater extent than the book collection. the journal collection handles needs more oriented towards high energy physics.

The Preprint Collection: The Preprint Collection holds pre-publication documents describing theory and experimental results in a pre-publication format (publication in journals can often take months). These documents are used to communicate rapidly the results of current research. Between 450-550 high energy preprints are received each month. These are cataloged locally (a Fermilab preprint number is assigned) and also for the benefit of the high energy physics community at large through the SPIRES (Stanford Public information Retrieval System) at Stanford Linear Accelerator Center (SLAC). The SLAC system generates cards at Argonne. These are then mailed to Fermilab and filed in the Library's preprint catalog. As one can see from the steps involved, the automation of the cataloging directly into an online public access catalog would simplify and improve the process.

Programmatically. this Collection has great importance. It provides written. detailed information on current theories and experimental results in high energy physics and closely related fields. As such, it can provide insight into ongoing research and/or suggest new directions of endeavor. This Collection is highly specialized towards high energy physics experiments and theories.

Commercial Database "Collection": The commercial database "Collection" is provided through subscription services to dial-up connections to such databases as Physics Abstracts. Engineering Index. Science Citation Index. etc. These provide immediate and. to some extent. "online" access to up-to-date subject and author bibliographies for researchers specific topics of study. The results of these searches provide references necessary either to locate sources within the Fermilab Library's own collection or to request the sources through the document delivery service of the Library. Hundreds of online databases are available through the Library's subscriptions to several vendors.

Programmatically. this is important when a researcher's activities take him or her outside the areas of collections actually held by the Library. Effectively. it becomes possible to greatly expand the library by this means at a lower cost than that needed to augment the permanent collection with the material.

\subsubsection{What are the Needs?}


The needs from a broad programmatic perspective are listed in the following paragraphs. Appendix A. "Specifications for Library Automation Software." lists the needs from a detailed Library perspective.

Wider Access: The Fermilab Library needs to provide wider access to its collections. Currently, a trip to the Library itself is required in order to determine whether items on a particular subject are present in the Library's collection. This is true even though the Laboratory is linked by computer terminals and networks both within Fermilab and to other laboratory and university locations.

Additional Search Methods: The Fermilab Library needs to provide the ability to search its collection by keyword. Currently. the traditional card catalog search allows researchers to look for an item by author. title, or subject. The "subject". though, is only that defined by the Library of Congress cataloging system-this is frequently not an appropriate subject categorization in a "high energy physics" sense.

More Capable Search Methods: The Fermilab Library needs to provide more capable search methods, such as the presence of keyword $A$ and keyword $B$.

Up-to-date Status Information: The Fermilab Library needs to provide more up-to-date status information on items in its collections. Currently. the status of an item may lag its actual status by several days due to the manual methods for sorting and shelving the items.

Online Information: The Fermilab Library needs to provide its information online and available to the other word-processing and computing facilities. Providing status information online will reduce the numter of needless trips to the Library only to find the item already checked out. Making catalog information available will improve the efficiency of the process in that it will enhance the likelihood that the items available are in fact what are required--before the trip to the Library is made.

Adherence to Standards: The Fermilab Library needs to base its automation on recognized standards within the computerized library field. In particular. the automated system must fundamentally base its operations on the MARC standard (MAchine Readable Cataloging standard) defined by the Library of Congress. This is necessary so that the Fermilab Library does not become dependent upon a proprietary code for the organization of its information. This is an important component to the adaptability and resiliency of the overall system in the face of the rapid technological change which is upon us.

Move towards "full text online": The Fermilab Library needs to position itself so that it may at some future date be able to supply the actual material itself online. In particular, a system which automates the day-to-day functions of the library and user catalog access functions must either:

1. be able to have the user catalog access functions transported to a system which does have the ability to supply full text online. or

2. be able to be expanded to accomplish the provision of full text online itself, or

3. be able to be networked to a system which is able to supply the full text online. 
Automate Day-to-Day Activities: The Fermilab Library needs to automate the day-today library tasks so that the Library staff can best be utilized in the service of the research needs of the Laboratory. Presently. the ordering. receiving, and cataloging of books. journals, and preprints involves much manual labor. Appendix A. "Specifications for Library Automation Software." lists in detail the needs which, if automated through an online system, would save time and make better use of resources.

Be Sized to Meet Initial and Projected Demand: The Fermilab Library must have a system whose disk capacity is able to provide storage space for the databases that comprise the system and whose CPU is able to provide good response time. These capabilities must be available initially for the current size of the collections and must be able to handle the projected growth in sizes of the collection and numbers of users accessing the system.

Be Highly Available: The Fermilab Library must have a system whose response time and availability is uniform and predictable. This is needed because the system is involved in the day-to-day functioning of the library. It is important that the check-out of materials, the interrogation of the catalog, and the like, be relatively independent of events unrelated to the library. System downtime must be scheduled around the needs of library operation--not the reverse.

Minimal Overhead: The Fermilab Library must accomplish these automation goals with a minimal increase in staff specialized solely to the support of "the computer" or "the automation system". The Library must be able to take advantage of the support staff that already exists in other areas of the Laboratory. Further, the system must be an "off-the-shelf" type of system needing little or no custom programming in order to adapt it to Fermilab.

Minimal Space and Environmental Requirements: The Fermilab Library must accomplish these goals within the 10 square feet available for the system and within the constraint that it must require only normal office environment for its operation.

To summarize. the needs from a broad programmatic perspective are:

1. Wider Access

2. Additional Search Methods

3. More Capable Search Methods

4. Up-to-date Status Information

5. Online Information

6. Adherence to Standards

7. Move towards "full text online"

8. Automate Day-to-Day Activities

9. Be Sized to Meet Initial and Projected Demand

10. Be Highly Available

11. Minimal Overhead

12. Minimal Space and Environmental Requirements

The needs from a specifically Library perspective are listed in Appendix A. 


\subsection{What is the Plan to Satisfy the Needs?}

The Library plans to satisfy the needs via a two-phased approach.

\section{Phase 1:}

Phase I will provide library automation for users and Library staff who are local to the Library. That is. Phase I will acquire and implement software and required hardware which will provide an online capability for:

1. managing the acquisitions of library materials.

2. cataloging existing and newly acquired materials in machine-readable (barcode) form.

3. tracking the circulation of those materials.

4. tracking and controlling serials (i.e., periodicals). and

5. providing online access to the "card" catalog by users within the Library proper-including providing the ability for users to do searches of the catalog according to both simple keywords and more complex combinations of keywords ("and". "or", etc.).

The Phase I plan is to acquire the Atlas ("A Total Library Automation System") software package from Data Research Associates. Inc.. a MicroVAX VMS system, to implement the library automation project using that software and equipment. and to label the existing collection via barcodes (as well as to continue to barcode material acquired in the future).

\section{Phase II Plan:}

Phase II will provide automation for users who are remote from the Library. Phase If will acquire and implement software which will provide an online capability for remote users to access the "card" catalog and do keyword searches as with the local capability.

In addition. Phase II will acquire and implement software which will download preprint updates into the online "card" catalog provided by Phase I. Phase II will acquire additional disk to support this capability and projected space increases due to the addition of materials to the online collection.

Specifically. Phase II will acquire the Online Public Access portion of the Atlas system for use on the Fermilab Central Facility VAX Cluster. will obtain a software program to do the necessary preprint information conversion. and, finally, will augment the disk with an amount required for the preprint and additional collections. 


\subsection{How will the Plan will Satiafy the Need?}

Wider Access: Wider access will be provided in Phase II through the ability of users remote from the Library to login to the Central Facility VAX Cluster and interrogate the Library "card" catalog. Because of its role as the central communication "hub", the Central Facility VAX Cluster is available over a wide area and via many access mechanisms. As a result. this will provide the widest possible online access to the Library catalog for remote users. No longer will it be necessary to physically go to the Library to determine the items in the collection.

Additional Search Methods: Additional search methods will be provided both in Phase 1 (to local users of the Library) and in Phase II (to remote users of the Library) via the keyword search capabilities of the Atlas Library Automation package. No longer will the only search keys be simply author, title, or subject--instead, it will be possible to search for particular words within a title (such as "photon" or "quark").

More Capable Search Methods: More capable search methods will be provided both in Phase I (to local users of the Library) and in Phase 11 (to remote users of the Library) via the Boolean "and" and "or" capabilities in association with the keyword search capabilities of the Atlas Library Automation package. No longer will one have to sift through all "photon" titles for those also containing "quark."

Up-to-date Status Information: Up-to-date status information will be provided both in Phase I and in Phase II via the capabilities of the Atlas Library Automation package to provide checked-out/" on-the-shelf" /on-order information through its online catalog query capabilities with such information updated as soon as it changes. The capabilities are provided to remote users in Phase $I I$ in a similar manner because of the direct access over DECnet to the primary databases on the Library MicroVAX. No longer will it be the better part of a day before the information that a book is returned is actually made available to other users of the Library.

Online Information: Online information about the items in the Library's holdings will be provided both in Phase $I$ and in Phase II via the capabilities of the Atlas Library Automation package to provide author, title. and subject classifications of the Library's holdings in an online manner. Online information in Phase $I 1$ will be made available directly in the user's own computer account for further integration into documents via word processing programs. No longer will it be necessary to construct bibliographies in online documents by transcribing the information from notes made off of the cards in the catalog.

Adherence to Standards: The selected Atlas system is based heavily on an adherence to well recognized standards promulgated by the National Information Standards Organization (NISO)--a branch of the American National Standards Institute (ANSI). In particular, the system implements the following standards:

NISO Z39.2-1985

NISO Z39.9-1979

NISO Z39.21-1980

NISO Z39.44-1986

NISO Z39.45-1983

NISO Z39.47-1985

NISO Z39.49-1985
MARC (MAchine Readable Cataloging Standard) International Standard Serial Numbering

Book Numbering

Serial Holdings Statement

Claims for Missing Issues of Serials

Extended Latin Alphabet Coded Character Set for Bibliographic Use

Computerized Book Ordering 


\section{NISO Z39.58-198X Common Command Language for Online Interactive} Information Retrieval

Most importantly for Fermilab purposes is the implementation of the first standard listed--the MARC format. The system not only accepts bibliographic and authority records in MARC format but it also is able to output already entered bibliographic and authority records in MARC format. This provides the interchangeability needed in an era characterized by a high rate of technological change so that the Library may move to a more technologically advanced system when it becomes available.

It should be also noted that Data Research Associates indicates that they are committed to implementation of additional standards within a short while after they are formally published. The standards in question are:

$\begin{array}{ll}\text { NISO Z39.50-198X } & \begin{array}{l}\text { Information Retrieval Service Definition } \\ \text { NISO Z39.55-198X }\end{array} \\ \text { NISO Z39.57-198X } & \begin{array}{l}\text { Holdings Statements for Non-Serial Items } \\ \text { Common Command Language for Online Interactive } \\ \text { NISO Z39.58 198XX }\end{array} \\ \begin{array}{ll}\text { Information Retrieval } \\ \text { NISO Z39.63-198XX }\end{array} & \begin{array}{l}\text { Interlibrary Loan Data Elements } \\ \text { Character Set for Chinese/Japanese/Korean. }\end{array}\end{array}$

Move towards "full text online": The Atlas system positions the Library for a future move to full text online according to all three of the criteria listed in Section 1.1.2. "Needs". In particular.

1. It is possible to get the cataloging data out of the Atlas system in MARC format for transporting to another system.

2. The MicroVAX VMS system used by the Atlas software is capable of being expanded both in the area of CPU and in disk by a very large amount.

3. The VMS system required by the Atlas software has the DECnet capability which allows for quite flexible networking to other systems.

Thus, the need to position the Library for a future move to full text online is well satisfied. The options of moving to a completely different system, expanding the MicroVAX system, and/or networking to another system are all available as ways of providing the full text online capability.

Automate Day-to-Day Activities: The day-to-day activities will be automated by the Atlas system. All the items listed as mandatory in Appendix $A$ are met by this system. In addition. most of the items listed as desirable are also met. (Those which are met are indicated by an asterisk.)

Be Sized to Meet Initial and Projected Demand: Projections of disk estimates from other Libraries using the Atlas software indicate that two 638 Megabyte disks should be adequate to hold the databases initially. Two additional 638 Megabyte disks are projected to be required to support Phase II's additional Preprint Collection requirements and the growth of the other collections.

Projections of CPU estimates from other Libraries using the Atlas software indicate that a CPU of approximately two to three VAX-11/780 equivalents should be adequate. 
These projections have factored in the additional load expected in Phase II from the network accesses. In this role. the system is acting as a server of the database systems--a role that has more compute-intensive requirements. Thus, the CPU requirements are increased in order to support such network activity.

Be highly available: The requested Atlas system on its dedicated MicroVAX is expected to be highly available. Discussions with sites currently using the Atlas system indicate that the Atlas software has been extremely reliable--no more than one day's downtime in two years of operation was the statement made by one site interviewed. Further. the telephone support in such a situation was classified as "excellent". The use of a dedicated MicroVAX. wherein the load can be controlled and insured to be of Library origination. will also result in a uniform and predictable response time.

Minimal Overhead: Tasks required of Library staff solely in support of "the computer" are expected to be minimal. The system is an "off-the-shelf" type of system. Once installation is complete, only the regular initiation of system backups and monitoring of the system overall for proper operation are expected to be necessary. Experience from other parts of the Laboratory indicates that at most two days of training should be required for these activities.

Minimal Space and Environmental Requirements: The space requirements of the requested dedicated MicroVAX system are within the 10 square feet allotted. The environmental requirements allow for operation within a normal office setting. 


\section{What are the Specific Items that will be Acquired?}

The Phase I items to be acquired together with their required features and the reasons for the requirements are:

Phase I Software:

1. License for Marion Bibliographic Database Module. This provides the bibliographic database software on which the Atlas system is based.

2. License for Circulation Module. This provides the circulation software required for the tracking of books that have been checked-out, etc.

3. License for Acquisitions Module. This provides the acquisition software required to track the acquisition of materials for the library.

4. License for Public Access Catalog Module. This provides the online public access software that users access in order to determine books in the Library.

5. DQS Distributed Queue System License. This provides access from the Library MicrovaX system to printers available elsewhere in the Laboratory. This is required in order to allow Library staff and users to print the results of their searches on printers convenient to their work locations.

6. License for VMS. This is required by the Library automation software in order that the system operate.

7. License for DECnet. This is required in order that installation of the other DEC software be possible and in order to support Phase II's requirement for remote access.

Phase I Hardware:

1. DV-340T2-A2 with CPU and 12 Mbytes of memory. Ethernet interface. License for VMS (10 User). DECnet, and 2 RF30 150 Mbyte disks in a BA213 Pedestal cabinet. A VAX or MicroVAX is required by the above Atlas Library automation software. This particular package provides the required capability at the cheapest cost. The CPU requirement of twoto-three VAX-11/780's is met by this particular model. The disk requirements for the VMS system are also met by this particular model.

2. Summus \#442 $8 \mathrm{~mm}$ tape cartridge drive and Q-bus controller with both disk and tape capability. This is required in order to load the VMS system and to perform system backups.

3. Two CDC 94181-638 Wren V 5.25" disk drives with SCSI Interface--638 Mbytes each. This is required in order to hold the projected size of the databases for the Library collections.

4. CK15-GU set of cables. This is required in order to connect the tape and disk to the CPU. 
5. Four VT320 Terminals. This is required in order to provide user access from within the Library to the system.

6. Talaris 800 Printer. This is required in order to provide the ability within the Library for the Library staff and users to obtain hardcopy results of their searches and (in the case of the Library staff) acquisition and other reports.

7. CXY08-AA Terminal Interface for 8 terminal lines. This is required in order to support the four user terminals and the four Library staff terminals.

Phase I Training. Documentation, Installation, etc.:

The training. documentation. installation, etc. are all provided by arrangement with Data Research Associates. Inc. These items are required in order to train Library staff in the operation of the system and to install the system properly configured and able to work.

Phase I Collection Preparation:

The collection preparation effort is described further in Appendix B. This effort includes barcoding the collection and entering into machine readable form the catalog records of all items in the Library not already so entered. This is required in order to proceed with the loading of the catalog into the Library database.

The Phase II items to be acquired together with their required features and the reasons for the requirements are:

1. License for Public Access Catalog Module. This is required in order to run the Public Access software on one of the nodes of the Central Facility VAX Cluster.

2. Program to convert SPIRES preprint records to MARC format. This is required in order to support the updating of the preprint collection.

3. Two additional CDC 94181-638 Wren V 5.25" disk drives. These are required in order to hold the preprint collection to be installed during the Phase II time period and to handle projected growth in the Library collection. 
3. What are the approximate coste?

The approximate costs are:

\begin{tabular}{lr} 
Phase I & \\
Software: & $50,000.00$ \\
Hardware: & $60,000.00$ \\
Training \& Inst.: & $25,000.00$ \\
Preparation: & $25,000.00$ \\
\hline Phase I Total: & $\$ 160,000.00$ \\
& \\
Phase II & \\
Software: & $25,000.00$ \\
Hardware: & $10,000.00$ \\
Phase II Total: & $\$ 35,000.00$ \\
Combined Total: & $\$ 195,000.00$
\end{tabular}




\section{What were the Factors in the Selection of ATLAS?}

An extensive survey and study of library automation systems was done during October 1988 through February 1989. Visits were made to several sites which had each implemented different automation systems. With this as the basis. the Automation Sub-committee of the Laboratory's Library Committee recommended the selection of the Atlas system provided by Data Research Associates. Inc. The Library Committee concurred. With the approval of the Implementation Plan by the U.S. Department of Energy, the acquisition process commenced.

Some of the considerations and conclusions that led to the selection of Data Research Associates. Inc. and Atlas are now presented.

\subsection{Available Systems during the October 1988-February 1989 Timeframe}

\subsubsection{Overview}

The available systems were examined with regard to their ability to meet the general needs described above and the more specific library needs described in Appendix A.

Certain of the general needs are unique to the Fermilab environment while others are typical of most libraries. Crucial to the success of the system in the Fermilab environment was its ability to satisfy the "wider access" criteria. While it would have been possible to interpret the "wider access" criteria so that any system that supported "dial-up" access would have passed, that was in fact not what was done. What was done was to look at the overall ability of the system to network to the rest of the laboratory in a smooth and seamless way.

This proved to be the essential pass/fail test.

More than ten different vendors were evaluated with regard to the ability of their product to satisfy the "wider access" criteria. Several vendors passed.

These vendors were then examined more closely both to determine their product's ability to meet the other general needs and to determine their product's ability to meet the specific Library needs. Visits to sites where the product was installed and actually in operation were made. Current customers were interviewed.

Of these vendors. only Atlas satisfied all the general needs and all the mandatories of the specific Library needs listed in Appendix A. 


\subsubsection{Detailed Consideration}

In sorting through the systems that were left, on closer inspection some were found to require a considerable amount of programming in order to achieve a complete Library automation system. Often. these systems were at their core a vendor's database management system with a skeleton layer that attempted to implement a library automation system on top of the core--that core being the vendor's main product.

Sites with such systems reported difficulties advancing to the latest versions (which had desirable features) because of the extensive customization that had occurred at their site. These systems failed on the "Minimal Overhead criteria".

Other systems allowed input in MARC format but either did not fully embrace the standard or did not allow export of data in such format. These systems failed on the "Adherence to Standards" criteria.

The Atlas system was found to be a complete packaged system. Its extensive parameterized approach allowed it to be adaptable without the necessity of reprogramming or re-"gen"-ing. While having a database system underlying its operation, it was a more completely integrated system than the other systems examined. What particularly recommended it over the other systems examined was its reliance on recognized, industrywide standards--both in the Library area and in the Computer area.

It supported MARC format both as input and as output. The user interface area was quite strong. It supported a full screen mode in which a user could give commands at a command window. Type-ahead, command recall, etc. were supported.

As for the "Wider Access" criteria, accessibility over DECnet was allowed. For example, two computer systems running ATLAS and connected by DECnet can point to each others "card" catalog. The result is that patrons can search and otherwise use the catalog of the other library in a straight-forward way. This capability makes the implementation of the Phase II aspects possible in a full and complete way. In addition, the system has the ability to support several library systems, each with several branches. and each of those with multiple departments provided an expandability--which, although not needed at present. is helpful to have in reserve. 


\section{APPENDIX A}

\section{Specificatione for Library Automation Software}

(* = Desirable Satisfied by Atlas: all mandatories satisfied by Atlas)

\section{GENERAL}

Mandatory:

A. Complete integration of acquisitions, serials. circulation, cataloging. and public access catalog modyles.

B. All modules in use for at least 6 months by more than 4 sites.

C. Dial-access is supported.

D. E-mail facility operable for electronic requests from users.

E. Output generator allows extraction of files for sorting, editing and printing, or production of statistics.

F. Supports multiple library sites (branches).

G. Source code will be made available to customer in case vendor can no longer support product.

H. Software portability is supported through the adherence to U. S. MARC (Machine-Readable Cataloging) standards.

I. Interface with SPIRES can be accommodated.

Desirable:

A. $D C L$ command interface to OPAC (online public access catalog) is possible. 


\section{ACQUISITIONS}

A. General

Mandatory:

1. On order status is available from OPAC.

2. Order records can be suppressed from OPAC.

Desirable:

1. The system shall provide a mechanism for the transmission of order records to Baker and Taylor.

B. Vendors file:

Mandatory:

1. Vendor records shall have fields for: (a) vendor name; (b) full address: (c) telephone number: (d) vendor account no.

2. Vendor data does not have to be re-entered for each purchase requisition.

C. Fund Account Records

Mandatory:

1. The system shall automatically post activities to fund accounts as items are ordered. received, and/or cancelled.

2. The system will allow all accounts tc be overexpended and will compute negative balances.

3. Generation of fund accounting reports shall be possible by individual funds and by the grand total.

D. Ordering:

Mandatory:

1. The system shall provide a check for existing records in the online public catalog prior to creation of acquisition record and shall notify operator if item is duplicate.

2. The system shall be able to process the following types of orders: (a) blanket purchase orders: (b) one-time purchase orders: (c) short orders: (d) deposit accounts: (e) standing orders: (f) gifts: (g) approvals.

3. The operator shall be able to order duplicates of materials already in a library's collection, on order, or in process.

4. An interface with OCLC records will be provided.

5. The system shall allow multiple copies of a selection to be charged to the same or different fund accounts.

6. An operator shall be able to overencumber in all accounts.

7. Order record will provide fields for the following information: (a) author/title or item description: (b) publisher; (c) publication date: (d) edition: (e) volume: (f) series: (g) ISBN or other item number: (h) quantity: (i) date of order; (j) purchase order or other account number: $(k)$ budget code or codes; (l) expected price: (m) requester/mail station/extension: 
(n) special instructions. i.e. Rush: (o) type of order, i.e. blanket, deposit. etc.

8. Of the above fields. the following may be searched in the acquisitions system: (a) author/title or item description: (b) date requested, i.e. < 6/1/88: (c) purchase order or other account number: (f) vendor: $(g)$ budget code.

Desirable:

1. The system shall print purchase requisitions in the Fermilab purchase requisition format.

2. Requester field is searchable.

D. Receiving:

\section{Mandatory:}

1. System shall automatically change the status of items on order to "received" when invoice details are recorded.

2. Facility for recording partial receipt of items related to an order is provided.

E. Claiming and Cancelling:

Mandatory:

1. System shall search and retrieve all records for materials which have been on order for over a specified amount of time but which have not been received.

2. An operator should be able to cancel an order at any time.

3. The system shall disencumber from fund account records the list prices of cancelled items and add the amounts back to free balances.

4. The system shall provide an online report of all items that should be claimed and that have been claimed.

\section{F. Reports:}

Mandatory:

1. Statistical reports shall include statistics for both month-todate and year-to-date sorted by fund account.

2. Statistics shall be provided for the number of records on order, received, claimed, cancelled, and in process.

Desirable:

1. Statistics shall be provided for vendor performance. 


\section{iII. ONLINE PUBlic CATAlog}

A. Bibliographic Records

\section{Mandatory:}

1. The system shall accept and differentiate between all bibliographic formats (monographs, serials, audiovisual media. sound recordings electronic data files, scores, maps, and manuscripts).

2. Local bibliographic data, such as local subject headings, notes, call numbers, etc.. shall be preserved if entered in bibliographic records through OCLC terminals.

3. Immediate indexing is provided for complete bibliographic records.

\section{B. Copy Records}

Mandatory:

1. The system shall accommodate and differentiate between the copy holdings of a minimum of 10 branches or agencies.

2. The system shall accommodate and differentiate between the copy holdings of a minimum of 20 separate collections within each branch library.

Desirable:

1. The system shall print spine labels for items.

\section{Authority Control}

\section{Mandatory:}

1. The authority control system shall include control for personal names, corporate names, meeting/conference names, uniform titles, series (both traced and untraced). geographic subject headings, and topical subject headings.

2. The system shall make global changes to all references to authority records.

Desirable:

1. The system shall accommodate the electronic transfer of individual authority control records from OCLC.

2. The system shall accommodate the batch loading of authority records from Blackwell and UTLAS.

\section{Database Creation and Maintenance}

Mandatory:

1. The system shall accommodate the electronic transfer of both individual bibliographic records from OCLC and batch loading from OCLC archival tapes.

2. The system shall accommodate the manual addition of tagged data to individual records. 
3. The system shall provide printout of call numbers for inventory purposes arranged in shelf list order.

4. Modifications or corrections in data fields of records shall be possible without retyping the entire line or data field.

5. The system shall be able to generate a magnetic tape in U.S. MARC format of all records in the database.

Desirable:

1. An online display or printout of encoding level match problems shall be generated to allow staff to make record replacement decisions.

E. Searches/Inquiries

Mandatory:

1. The following fields are searchable:

a. personal author

b. corporate author

c. title

d. author/title combination

e. series title

f. subject heading

8. keyword

h. call number

i. ISBN. ISSN. OCLC numbers

j. customer-specified fields, such as place of conference. conference title

k. combination of above

2. Boolean operators "and." "or." "not" are supported.

3. Command-driven retrieval is available.

4. Automatic truncation is provided.

5. A new search may be initiated at any point.

6. The system shall permit browsing through the catalog by allowing users to display index entries in the alphabetic neighborhood of the terms entered.

7. The system shall not be case-sensitive.

8. The system shall ignore variations in the punctuation of Library of Congress subject headings.

9. The system shall support a break key or similar feature which will allow users to interrupt long searches.

10. Help screens are available at any point within a search.

Desirable:

1. Menu-driven search format is accessible for occasional and beginner users.

2. Search sets can be saved for further combinations with each other or with new search strings.

3. Searches can be qualified by date of publication and by a range of dates.

4. The system shall allow paging forward and backward from a specific point in all searches.

5. The system shall guide the user in continuing a search if no match is found. 
6. Searcher can type ahead.

7. The system shall have an online tutorial on using the catalog and conducting searches.

8. Help messages may be customized.

\section{F. Search Results}

Mandatory:

1. If an exact match is made, the full bibliographic record will be displayed.

2. When a search yields more than one match, a brief record is retrieved which allows the searcher to choose by number a record or records for full display.

3. The system shall indicate the status of the items displayed (on order. in circulation, available. lost. missing. etc.)

4. The system shall indicate location for each item displayed.

5. Search results may be forwarded to the searcher's computer account to which the Library computer is connected.

\section{Desirable:}

1. The system shall enable the user to specify the sort order of a listing by author. title, etc.

\section{G. Statistical Reports}

\section{Mandatory:}

1. Statistics shall be provided for the number of titles and copy records currently in each database.

Desirable:

1. Each statistical report shall include statistics for both monthto-date and year-to-date.

2. Statistics shall be provided for the number of times "help" requests are made.

3. Statistics shall be provided for the number of searches through each index (author, title, subject. call number, etc.) 


\section{CIRCULATION}

A. General

Mandatory:

1. The status (in circulation, available. lost, at bindery, etc.) of circulating materials on the system shall be shown in the public online catalog.

2. Input of user and item identifier. for both charges and discharges. may be accomplished by barcode reader or manually. using keyboard.

3. Immediate update of user and item record in all circulation transactions.

Desirable:

1. The system shall be able to disable the calculation and recording of fines and fees.

2. Notices for overdues, recalls, etc. shall be able to be generated and sent by the system via electronic mail.

\section{B. Borrower Control}

Mandatory:

1. The system shall provide for borrower records which include the following data as a minimum:

a. borrower identification number

b. borrower surname and first name

c. local address

d. local telephone number

e. expiration date of authorization to borrow

f. status of employment

2. Borrower records can be created and edited manually online.

3. Authorized staff may view all active loans by a designated borrower.

\section{Desirable:}

1. The system shall accommodate the batch loading of borrower records using data supplied by the Personnel Records department.

2. Borrower can see his own loans records with due dates -accessed only by his unique identifier number.

3. The system shall provide for borrower records which include the burrower's local computer account node and username on the network to which the Library computer is connected.

\section{Charge Activities}

Mandatory:

1. The system shall notify the operator if a borrower is not registered and shall allow the Librarian the option of proceeding or not as required.

2. The system shall verify that material is not on hold for another borrower. 
3. The system shall verify that material is allowed to circulate before it is charged to a borrower.

4. The system shall permit charges to library units (e.g. ILL. binding. etc.).

5. The system shall allow due dates to be changed online by authorized password.

Desirable:

1. The system shall print at the charging location a due date slip to be inserted in the charged item.

D. Renewal Activities

Mandatory:

1. The system shall calculate and display the new due date for renewals.

2. The system shall check the circulation file for holds on items to be renewed, shall block renewal if holds are found, and shall prompt hold processing.

Desirable:

1. A provision is provided for remote renewal by user in case of no hoids pending and no other restriction activated.

\section{E. Discharge Activities}

Mandatory:

1. The system shall disassociate the loan from the borrower and shall remove the record from the circulation file .. for the privacy of the borrower.

2. The system shall check for holds, shall signal the operator if they are found, and shall prompt for appropriate processing.

\section{F. Holds and Recalls}

Mandatory:

1. The system shall allow holds to be placed on materials in circulation.

2. When a hold is placed. the system shall generate recall notices to borrowers.

3. The system shall prepare and print recall notices to borrowers that items on hold are available.

4. The system shall allow authorized staff to override the automatic sequence of processing holds.

\section{Desirable:}

1. The system shall generate a report of items which are in heavy demand. such that the number of holds placed on the same item exceeded a library-specified number. 


\section{G. Overdues}

Mandatory:

1. The system shall generate and print overdue notices to borrowers.

2. The library shall be able to specify the number of days to wait after a due date before overdue notices are generated.

3. Overdue notices shall include the following data:
a. borrower identification number and name
b. address and phone number
c. item identification including item number, call number. author, and brief title
d. due date of overdue item
e. date of notice

4. The system shall be able to generate a list of borrowers holding overdue items.

Desirable:

1. Overdue notices shall include the borrower's computer node and username.

2. The system shall be able to send electronic mail to the borrower's computer node and username notifying the user of overdue items.

\section{H. Circulation System Statistical Reports}

\section{Mandatory:}

1. Statistical reports shall include statistics for both month-todate and year-to-date activities.

2. The following reports may be generated:
a. number of charges. discharges, and renewals
b. call number groupings of (a)
c. number of overdues and recalls
d. number of times a given item has been charged
e. number of items recorded as lost. missing

\section{Desirable:}

1. The system shall compile a list of items which have circulated over a library-specified number of times within a year. 


\section{PERIODICALS CONTROL}

\section{A. General}

Desirable:

1. Online interface with Fermilab Library's subscription agent, Readmore, for orders, renewals, claims, etc.

2. For issues at the bindery, OPAC will show appropriate status.

B. Check-in

Mandatory:

1. Current date is entered by default.

2. Provision is made to check-in indexes. supplements, or other special issues.

Desirable:

1. Check-in data is accessible from OPAC. with most recent issues listed first.

C. Routing

Mandatory:

1. System will maintain a routing list file for specified periodical titles.

Desirable:

1. System will print routing slips.

D. Claiming

Desirable:

1. Based on predictions of publication frequency entered by systems operator. the periodicals module will identify missing or overdue issues.

2. Standard reports can be generated relating to missing/overdue issues and claims. 


\title{
APPENDIX B
}

\author{
Subsidiary Efforte
}

Three subsidiary efforts are necessary to prepare the Fermilab Library Collection for Automation: barcoding the book collection, performing a retrospective conversion of card files, and preparing the patron database.

Barcoding: The library's collection of monographs, i.e. books, conference proceedings. reference sources, were barcoded. This was done with "smart" barcodes provided by Data Research Associates. Inc. as part of their contract. The "smart" barcodes (which had the book's author and title in readable form along with the "zebra" stripe and the barcode number) were put onto the books in four-to-six weeks with the volunteer help of Library Science students from Northern Illinois University.

After some discussion. it was decided to place the barcodes on the front of the book just above the title if present. The reason is that the goal eventually is to allow patron charging of library materials. With the barcode on the front, it was felt it would be obvious to even the newest patron how to find the barcode.

The barcoding of the library collection will continue, of course, even after the system goes "online" as new items are received and as items not on the shelves are returned.

Retrospective Conversion: The retrospective conversion (i.e.. turning the existing "card" catalog into machine-readable form) was contracted out to the vendor which presently provides most of the library's bibliographic records and with whom the library's holdings are listed.

This effort took some foum months (October 1989 - January 1990) with a monthly tape being sent to the library for transmission to the automation vendor. At the end of this process, the automation vendor provided a tape containing the bibliographic information in a form suitable for loading into the online database. This was done in February 1990.

The estimated costs for these once only activities is $\$ 26,000.00$.

Preparing the Patron Database: The patron database will be downloaded on a weekly basis over DECnet from the online telephone book. The latter is updated weekly from the Personnel Database. Thus, the patron database will be well-synchronized with name and address changes, etc. using the information consistent with that held by other laboratory entities. The patron's "library card" will be his/her Fermilab Id card. The intent is to propose to the vendor the development of a confidential "PIN" number so as to allow patron self-charge of books and yet retain some degree of reliability of charge/discharge records.

File: FERMILAB_LIBRARY_PRJ\$HROOT:[MASS11]RFP.AJ3 Mass11 Directory and Document: [RFP]AUTOMATION

DOCDB Designation: IN-298 